\title{
Bleaching Microcrystalline Cellulose Using Hydrogen Peroxide, Peracetic Acid, and Ozone
}

\author{
Riku Kopra, ${ }^{\mathrm{a}, *}$ Kari Vanhatalo, ${ }^{\mathrm{b}}$ Sonja Päärnilä, ${ }^{\mathrm{b}}$ Antti Pappinen, ${ }^{\mathrm{a}}$ and Olli Dahl ${ }^{\mathrm{c}}$ \\ AaltoCell ${ }^{\mathrm{TM}}$ based microcrystalline cellulose was bleached using hydrogen \\ peroxide, peracetic acid, and ozone. The target brightness was set at $85 \%$ \\ ISO brightness of the sheet (93\% Y-brightness), which is white enough for \\ the traditional use of microcrystalline cellulose. Both the paper pulp and \\ dissolving pulp can be hydrolyzed using the AaltoCell ${ }^{\mathrm{TM}}$ process. Using \\ paper pulp as a raw material, the brightness of the final microcrystalline \\ cellulose decreased. The higher the temperature and retention time during \\ the hydrolysis process, the greater the brightness loss. This effect can be \\ explained by the so-called caramelization reaction. Due to this \\ phenomenon, the microcrystalline cellulose should be bleached before \\ using the product in food and pharmaceutical applications. The results \\ showed that the target brightness was reached with ozone at doses of \\ approximately $5 \mathrm{~kg} / \mathrm{ton}$ with a reaction time of a few minutes; peroxide and \\ peracetic acid required approximately twice the dose and a reaction time \\ of at least $30 \mathrm{~min}$. The concentrations of the chemical oxygen demand and \\ total organic carbon in the pulp filtrate fraction varied with the bleaching \\ chemicals used, with both values being low with ozone and the highest \\ with peracetic acid.
}

Keywords: AaltoCell ${ }^{\mathrm{TM}}$; Acid hydrolysis; Caramelization; Bleaching; Microcrystalline cellulose

Contact information: a: FiberLaboratory, South-Eastern Finland University of Applied Sciences, Vipusenkatu 10, Savonlinna 57200 Finland; b: Andritz Ltd., Fiber Technologies Division, Tammasaarenkatu 1, Helsinki 00180 Finland; c: Aalto University, School of Chemical Engineering, Vuorimiehentie 1, Espoo 02150 Finland; *Corresponding author: riku.kopra@xamk.fi

\section{INTRODUCTION}

Microcrystalline cellulose (MCC) is partially depolymerized cellulose, with a low degree of polymerization. It is a powder-like product invented in the 1950s by Battista, patented in 1961 by Battista, and was first commercialized under the brand name Avicel ${ }^{\circledR}$ (Battista 1950). Since then, the MCC process has been studied and developed by several research groups (Toshkov et al. 1976; Delong 1986; Bergfeld and Seifert 1996; Ha et al. 1998; Hanna et al. 2001; Jollez et al. 2002; Mattheson et al. 2002; Schaible and Brinkman 2003; Nguyen 2004; Ioelovich and Leykin 2005; Schaible and Sherwood 2005; Nguyen and Tan 2006; Frangioni and Frangioni 2016; Tan et al. 2016; Valchev et al. 2020).

Currently, MCC is used mostly in pharmaceutical and food industry applications. All lignocellulose sources that contain crystalline cellulose can be used as a raw material for MCC. A classic process for MCC production is performed using strong acid hydrolysis and a low consistency of dissolving pulp (Battista et al. 1961). The degree of polymerization (DP) level of chemical pulp is typically 500 to 2000, whereas for MCC, that number is less than 400. Any MCC particles with a size lower than $5 \mu \mathrm{m}$ must not form more than $10 \%$ of the total particles (FAO 1996). Lately, a novel way to produce MCC has been developed, called AaltoCell ${ }^{\mathrm{TM}}$; this process is performed using mild acid 
hydrolysis and a short retention and has a high operating consistency (Dahl et al. 2016). These features enable MCC to be produced at a high capacity, and the entire production line can be installed in a chemical pulp mill. In addition, paper pulp can be used as a raw material. This allows the production of pure carbohydrates, in the form of monomers, which can be used for production of other biobased products, e.g., biogas, bioethanol, PLA.

When cellulose is hydrolyzed in the traditional way via strong acid hydrolysis, the DP of the glucose units in the cellulose molecule chain is reduced. The acid hydrolysis product mixture contains dissolved carbohydrates. As such, 5-hydroxymethylfurfural is formed from glucose decomposition (Kupiainen 2012); it then decomposes into levulinic acid and formic acid under those conditions, and the decomposition rate is highly affected by an increase in temperature (Girisuta et al. 2006). Hemicelluloses degrade to form furfural, and this process is followed by further decomposition into organic acids and condensation reactions to form humin-like substances (Sumerskii et al. 2010).

In the AaltoCell ${ }^{\mathrm{TM}}$ process, MCC can be produced from fibrous cellulosic material via mild sulfuric acid hydrolysis at a consistency greater than $8 \%$ and a temperature greater than $120{ }^{\circ} \mathrm{C}$. In addition to temperature, consistency, and a low chemical dosage, the hydrolysis process of MCC is considerably affected by the hydrolysis time. The intensity of the hydrolysis treatment greatly affects the brightness of the solid residue. This effect is determined by the time and temperature, which can be expressed as the hydrolysis factor (P-factor), which allows the comparison of hydrolysis at different temperatures, for example (Sixta 2006). With longer hydrolysis times when using paper pulp as a raw material with a constant temperature, the solid residue becomes brown in color, as shown in Fig. 1 (Vanhatalo and Dahl 2014).

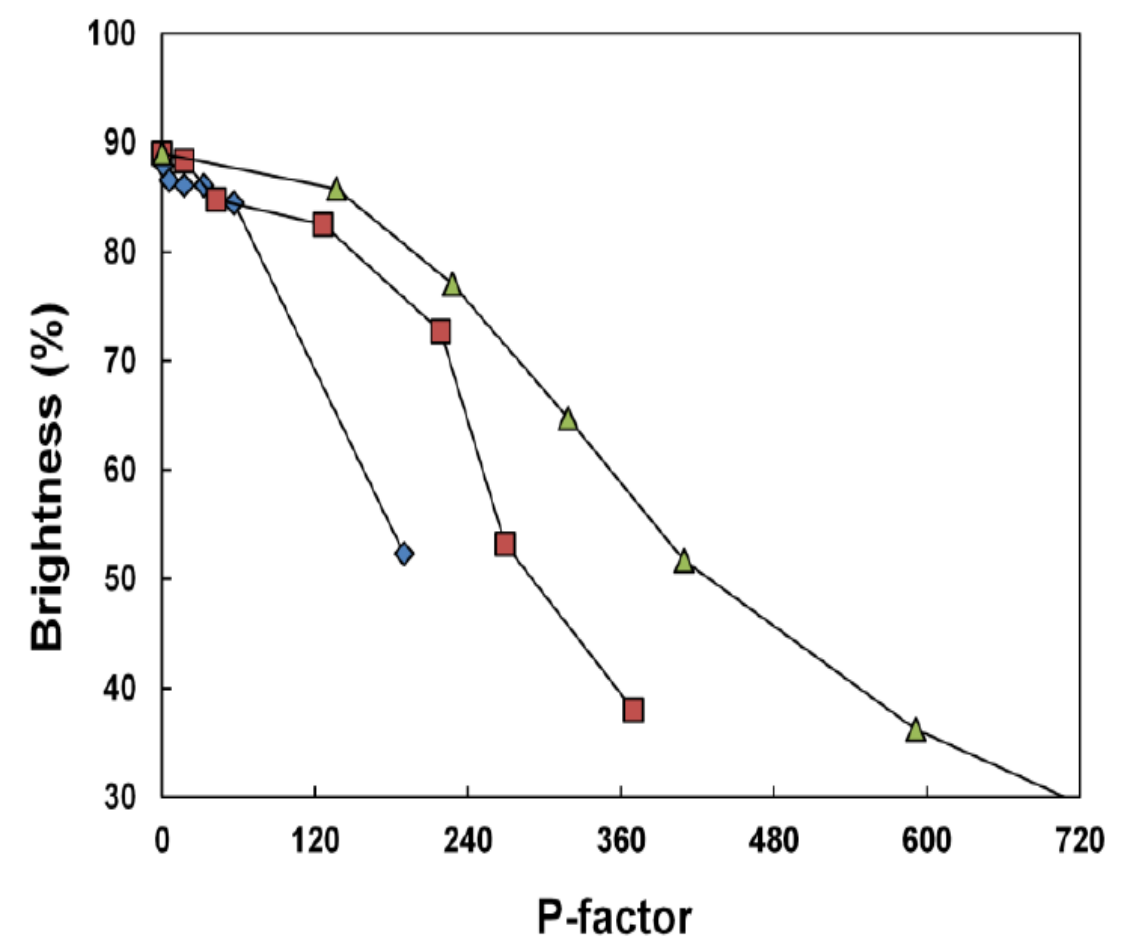

Fig. 1. The ISO brightness as a function of the P-factor. Note: the hydrolysis temperature levels were $120^{\circ} \mathrm{C}(\diamond), 140^{\circ} \mathrm{C}(-\square)$, and $160^{\circ} \mathrm{C}(--)$, the $\mathrm{H}_{2} \mathrm{SO}_{4}$ dosage was $1.5 \%$, and the consistency was $10 \%$; the raw material grade used was softwood paper pulp (Vanhatalo and Dahl 2014). 
The phenomenon that is apparent in Fig. 1 is likely due to decomposition (dehydration) and condensation reactions (caramelization), which carbohydrates undergo in acid media at elevated temperatures. This topic has been primarily studied in the food industry (Hodge 1953; Ledl and Schleicher 1990; Cui 2005; Lichtenthaler 2011). However, Valchev et al. (2020) have also investigated the phenomenon and state that due to the formation of caramelized sugar, the brightness of the MCC from paper grade pulps is drastically lowered at the end of the hydrolysis process. One likely option for the brightness loss is that sulfuric acid reacts with carbohydrates to form pure black carbon after caramelization.

The definition of MCC brightness is "white or almost white" (European Directorate et al. 2011). Thus, there is no clear target value of brightness that should be reached. As such, MCC producers often use their own in-house methods to measure color, which makes it challenging to compare different MCC grades from different producers. However, for food and pharmaceutical applications, a high MCC brightness is required. The hydrolysis conditions can be chosen to minimize the brightness reversion, which keeps the brightness at an acceptable level. However, to attain an extremely high MCC brightness (ISO 90\%), the hydrolyzed solid residue should be bleached with an oxidative agent, e.g., ozone, oxygen, or peroxide (Vanhatalo and Dahl 2014). These chemicals are normally used for kraft pulp bleaching processes to increase the brightness of the pulp via lignin removal or lignin decolorization; however, in this case, the chemicals are used for the removal of caramelized products from the MCC.

The oxidation power of the bleaching chemicals can also be expressed by the oxidation equivalent unit (OXE). The values for different bleaching chemicals are shown in Table 1. However, a high OXE charge is not a guarantee of high brightness. The bleaching process is a complex situation if the operation economy, pulp quality, and environmental aspects are simultaneously considered. However, its usage could be a valuable tool when the design and performance of bleaching sequences are discussed (Grundelius 1993; Chirat et al. 2003; Lachenal and Chirat 2005).

Table 1. Conversion Factors to Oxidation Equivalents (OXE)

\begin{tabular}{|c|c|c|c|c|}
\hline & $\begin{array}{l}\text { Molecular } \\
\text { Weight }\end{array}$ & $\begin{array}{l}\mathrm{e}^{-} / \mathrm{mol} \text { for Reduction to } \mathrm{Cl}^{-} \\
\text {and } \mathrm{O}^{2-} \text {, Respectively }\end{array}$ & $\mathrm{g} / \mathrm{mol} \mathrm{e}$ & OXE/kg \\
\hline $\mathrm{Cl}_{2},(\mathrm{C})$ & 70.91 & 2 & 35.46 & 28.20 \\
\hline $\mathrm{ClO}_{2,}(\mathrm{D})$ & 67.46 & 5 & $13.49^{*}$ & $74.12^{* *}$ \\
\hline $\mathrm{NaClO},(\mathrm{H})$ & 74.45 & 2 & $37.22^{*}$ & $26.86^{* \star}$ \\
\hline $\mathrm{O}_{2},(\mathrm{O})$ & 32.00 & 4 & 8.00 & 125.00 \\
\hline $\mathrm{H}_{2} \mathrm{O}_{2},(\mathrm{P})$ & 34.02 & 2 & 17.01 & 58.79 \\
\hline $\mathrm{O}_{3},(\mathrm{Z})$ & 48.00 & 6 & 8.00 & 125.00 \\
\hline $\mathrm{CH}_{3} \mathrm{CO}_{3} \mathrm{H}(\mathrm{Paa})$ & 76.05 & 2 & 38.03 & 26.30 \\
\hline \multicolumn{5}{|c|}{$\begin{array}{l}\text { Note: }{ }^{*} 35.46 \mathrm{~g} \text { active chlorine/mol } \mathrm{e}^{-* *}{ }^{\star} 28.20 \mathrm{OXE} / \mathrm{kg} \text { active chlorine; modified from Grundeliu } \\
\text { (1993) }\end{array}$} \\
\hline
\end{tabular}

To the best of the authors' knowledge, this is the first extensive study related to MCC bleaching. This work only focused on chlorine-free alternatives, i.e., ozone, peroxide, and peracetic acid (ePaa). This research created a basis for developing the production of high-brightness MCC made with AaltoCell ${ }^{\mathrm{TM}}$, using paper pulp as a raw material.

Kopra et al. (2021). "Bleaching of AaltoCell ${ }^{\mathrm{TM}}$ cellulose," BioResources 16(4), 7991-8005. 7993 


\section{EXPERIMENTAL}

Never-dried bleached softwood kraft pulp, supplied from a Scandinavian pulp mill, was used as the cellulose raw material. The degree of polymerization (DP) was 2590, and the ISO brightness (ISO) was $89 \%$. Dilute acid hydrolysis was performed in a $220 \mathrm{~L}$ cooking screw under the following conditions: a temperature of 160 to $170{ }^{\circ} \mathrm{C}$ and a reaction time of approximately $30 \mathrm{~min}$. The temperature was controlled by steam, and the time adjustment was controlled by changing the screw speed. The hydrolysis agent was $\mathrm{H}_{2} \mathrm{SO}_{4}$ (93\%, CAS 7664-93-9). The acid addition was about $1.2 \%$ of the pulp dry content based on the AaltoCell ${ }^{\mathrm{TM}}$ method with no mechanical treatment. The short delay is an integral part of the AaltoCell ${ }^{\mathrm{TM}}$ process and enables $\mathrm{MCC}$ production on a large scale at pulp mills. The AaltoCell ${ }^{\mathrm{TM}}$ manufacturing process in the experiments is shown in Fig. 2.

After hydrolysis, the MCC was fully washed using a belt washer. The values of the MCC were as follows: a DP of 320, an average particle size of $23.0 \mu \mathrm{m}(\mathrm{d}(0.5))$, an ISO brightness of $57 \%$, a pH of 4.1, and a consistency of $34 \%$.

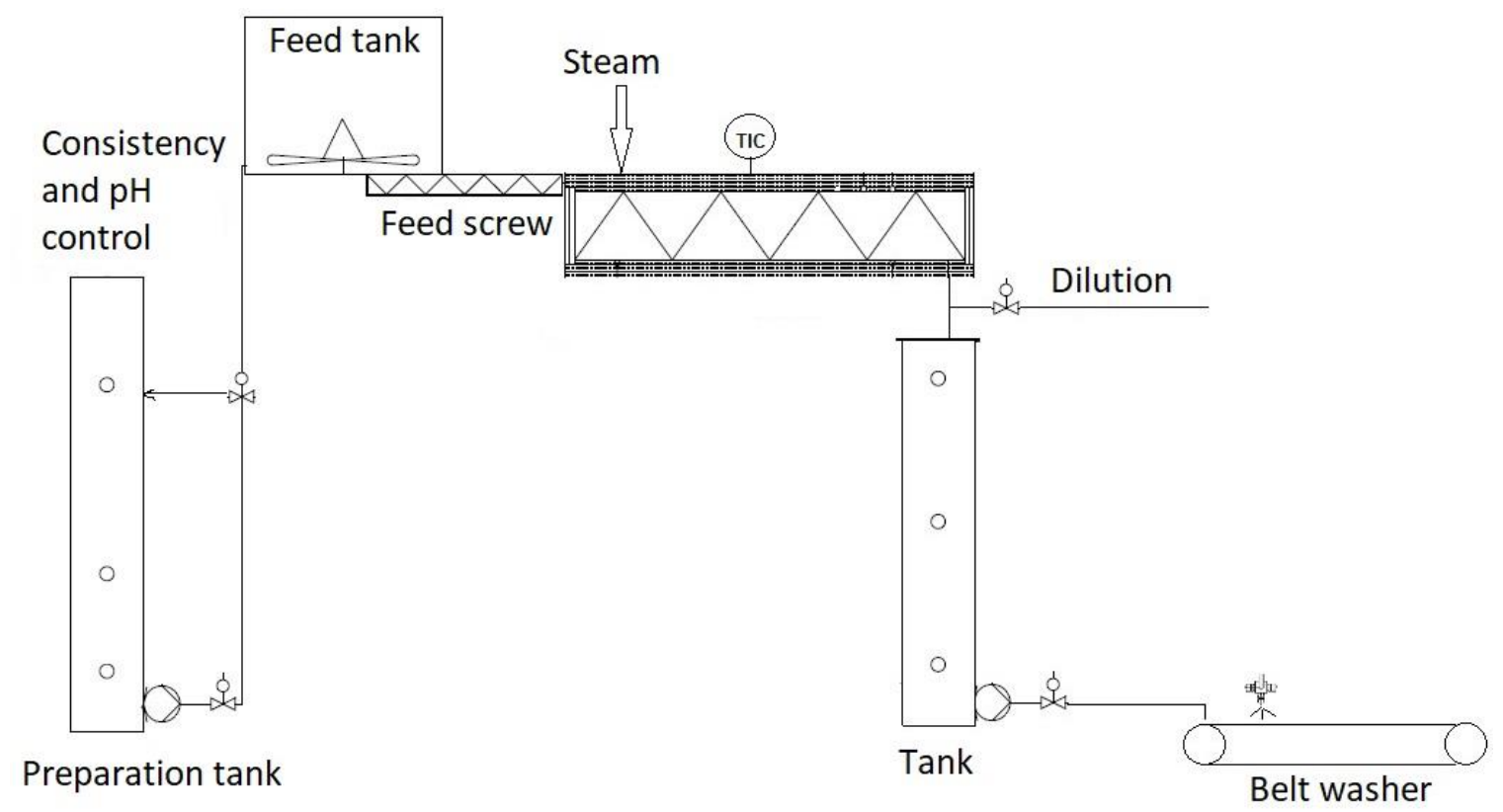

Fig. 2. Schematic diagram of the AaltoCell ${ }^{\mathrm{TM}}$ process on the pilot scale

\section{Preparing of the Chemicals}

The concentration of the laboratory purchased ePaa used was about 38 to $40 \%$. The ePaa was diluted to $10 \%$ for dosing. The concentration of peracetic acid and peroxide in the ePaa was analyzed by titration using the Evonik GmbH method (Author unknown 2020). The dosages were calculated as for the peracetic acid. The hydrogen peroxide used was about $30 \%$ laboratory quality. The peroxide was diluted to $10 \%$ for dosing. The strength was calculated using following formula,

$$
A=\frac{(B * 1.7)}{C}
$$

where $A$ is the hydrogen peroxide concentration $(\mathrm{g} / \mathrm{L}), B$ is the volume of $0.1 \mathrm{~N}$ sodium thiosulfate $(\mathrm{mL})$, and $C$ is the volume of hydrogen peroxide $(\mathrm{mL})$. The hydrogen peroxide residual was calculated using the following formula, 


$$
A_{\text {Residual }}(\mathrm{g})=\frac{(B * 1.7 *[C * D)-D])}{E * 1000}
$$

where $A$ is the hydrogen peroxide residual (g), $B$ is the volume of $0.1 \mathrm{~N}$ sodium thiosulfate, $C$ is the pulp consistency (\%), $D$ is the oven dry pulp sample weight (g), and $E$ is the volume of filtrate $(\mathrm{mL})$. The chemicals were dosed per ton of pulp in all cases.

\section{Bleaching Conditions}

The bleaching tests were performed using a Quantum Mark IV laboratory mixer (Quantum Technologies Inc., Akron, Ohio). The mixer has a 4.1 L Teflon coated reactor housing and mixer rotor. The mixer has a $7.5 \mathrm{kw}$ motor connected to the rotor shaft by a belt drive. The maximum speed of the mixer is $2400 \mathrm{rpm}^{-1}$. The reactor housing was surrounded by a heat mantle, where heated rapeseed oil was used to stabilize the temperature. The test equipment also included temperature and pressure measurements as well as data acquisition for the measurements.

A MCC pulp with a $34 \%$ consistency was diluted to $13 \%$ and added to the kettle. At the same time, an initial $\mathrm{pH}$ adjustment was performed with $\mathrm{NaOH}$. The pulp was preheated in a kettle and then poured into the preheated reactor. The chemical dosage of the peroxide or ePaa was added to the reactor, and then the cover of the reaction was closed. The starting temperature in the reaction was approximately $75^{\circ} \mathrm{C}$. The starting $\mathrm{pH}$ of 13 was chosen because there was a certain end $\mathrm{pH}$ target of about 4.5. According to unpublished results, an end $\mathrm{pH}$ of 4.5 is advantageous to get a good bleaching result. The peroxide in the ePaa solution is more active at the beginning of the reaction under alkaline conditions and the peracetic acid again in the acidic range. In practice, peracetic acid is a delignifying bleaching chemical, and its action was directed in the bleaching direction by raising the $\mathrm{pH}$. In this work, it was assumed that lignin was not bleached, but rather any caramelized sugars were bleached. Accordingly, the initial situation was different from that present in a standard pulp mill. The ozone dosing was performed differently, as described later. The bleaching conditions are shown in Table 2.

\section{Table 2. Bleaching Conditions for Microcrystalline Cellulose (MCC) Pulp}

\begin{tabular}{|c|c|c|c|c|c|c|c|}
\hline & $\begin{array}{c}\text { Concentration } \\
(\%)\end{array}$ & $\begin{array}{c}\text { Dosage } \\
(\%)\end{array}$ & OXE/ton $\mathrm{Mcc}^{*}$ & $\begin{array}{c}\mathrm{pH} \\
\text { Control }\end{array}$ & $\mathrm{pH}_{\text {start }}$ & $\mathrm{pH}_{\text {end }}$ & $\begin{array}{c}\text { Sampling } \\
(\mathrm{min})\end{array}$ \\
\hline Ozone & 10 & 0.7 & 875 & $\begin{array}{c}\text { Drop of } \\
\mathrm{H}_{2} \mathrm{SO}_{4}\end{array}$ & 3.3 & 3.0 & 1,3 , and 5 \\
\hline Peroxide & 13 & 1.3 & 764 & $\begin{array}{c}1.3 \mathrm{wt} \% \\
\mathrm{NaOH}\end{array}$ & 13.0 & 10.5 & $\begin{array}{c}3,10,20, \\
\text { and 40 }\end{array}$ \\
\hline ePaa & 13 & 1.6 & 421 & $\begin{array}{c}0.9 \mathrm{wt} \% \\
\mathrm{NaOH}\end{array}$ & 13.0 & 4.5 & $\begin{array}{c}3,10,20, \\
\text { and 40 }\end{array}$ \\
\hline
\end{tabular}

The pulp was stirred for $15 \mathrm{~s}$ at $2400 \mathrm{rpm}^{-1}$, after which stirring was continued at a slower speed $\left(120 \mathrm{rpm}^{-1}\right)$ during the reaction. A sampling of the pulp with ePaa and peroxide tests from the reactor over a time schedule (3 $\mathrm{min}, 10 \mathrm{~min}, 20 \mathrm{~min}$, and $40 \mathrm{~min}$ ) was performed using compressed air. Air was vented into the reactor from the valve to obtain a sample from the other valve.

For the ozone bleaching process, the chemical dosage was calculated by the volume 
remaining in the reactor and the pressure of the gas fed to it. The amount of pulp in the reactor was calculated using the density of the MCC at a consistency of $10 \%$ using a density value of $1000 \mathrm{~kg} / \mathrm{m}^{3}$. The preparation of the pulp was performed as previously described. In the reactor, the pulp was stirred at $2400 \mathrm{rpm}^{-1}$ for $10 \mathrm{~s}$. During the initial stirring, ozone was fed into the reactor through a valve and then continuously stirred at a slower speed $\left(120 \mathrm{rpm}^{-1}\right)$ during the reaction. The measurement of the residual ozone was performed by opening a valve from which the remaining pressurized gas was led to the ozone concentration meter. When the reactor pressure was at atmospheric pressure, the reactor cover was opened, and the bleached pulp was recovered for analysis.

The recovered pulp from all test points was filtered through blotting paper $(12 \mu \mathrm{m})$ in a Buchner funnel. The filtrate was collected for further analysis. The pulp was then washed three times (until the filtrate was clear). In the case of the peroxide and ePaa bleaching, the amount of residual chemicals were also titrated from the filtrate. Due to the tablet ISO brightness analysis, the water contained in the pulp was displaced with ethanol for drying, storage, and further processing. The chemical dosages were chosen to achieve a final ISO brightness of approximately $85 \%$.

\section{Analytical Determinations}

The samples were analyzed using the following methods: determination of the dry matter content (analytical) according to ISO standard 638 (2021); the chemical oxygen demand (COD) liquor samples were filtrated using $0.45 \mu \mathrm{m}$ paper and then analyzed in a COD analyzer according to ISO standard 15705 (2002); the total organic carbon (TOC) was determined with a total organic carbon analyzer (Shimadzu, Kyoto, Japan) according to ISO standard 8245 (1999); the $\mathrm{pH}$ was determined with a Mettler Toledo conductivity meter (Columbus, OH); the ISO brightness (sheet) was determined with an Elrepho analyzer according to ISO standard 2469 (2014); the ISO brightness (tablet) was determined with an Elrepho spectrophotometer, using tablets pressed from powders according to SCAN-P standard 89 (2003); the whiteness (W) was calculated according to ASTM standard E313 (2020), where an object having whiteness of $100 \%$ is considered perfect white; the monosaccharide composition was determined via high-performance anion-exchange chromatography with pulsed amperometric detection (HPAEC-PAD) after the sulfuric acid hydrolysis (Sluiter et al. 2006).

The viscosity was analyzed according to SCAN-CM standard 15 (1999) and then converted to DP according to SCAN-CM standard 15 (1988); and the particle size was determined with a Mastersizer 2000 (Malvern Panalytical, Malvern, United Kingdom) according to ISO standard 13320 (2009).

In addition, the Y-brightness and whiteness were measured from the powder samples using HunterLab's ColorFlex 45/0. The sample was put into a clear glass cup, and the reading was performed though through the bottom of the cup. The Y-brightness is one of the three tristimulus values XYZ of the tristimulus scale. It describes the ability of the sample to reflect green wavelength light, whereas the ISO brightness represents the reflectance of blue wavelength light. The human eye interprets objects as white when they have a blue hue to them. This is why the Y-brightness actually describes the grayness more so than the whiteness of a sample. The Y-brightness was calculated according to ASTM standard E308 (2018) and CIE 15.2 (Carter et al. 2018).

Kopra et al. (2021). "Bleaching of AaltoCell ${ }^{\mathrm{TM}}$ cellulose," BioResources 16(4), 7991-8005. 7996 


\section{RESULTS AND DISCUSSION}

\section{Bleaching and Chemical Consumption}

The results showed that using peroxide and peracetic acid required additional bleaching time compared to when ozone was used as the bleaching agent (Fig. 3). This was also the assumption before the tests, since ozone is known to be an effective bleaching agent and only requires a few minutes of bleaching when using chemical pulps.

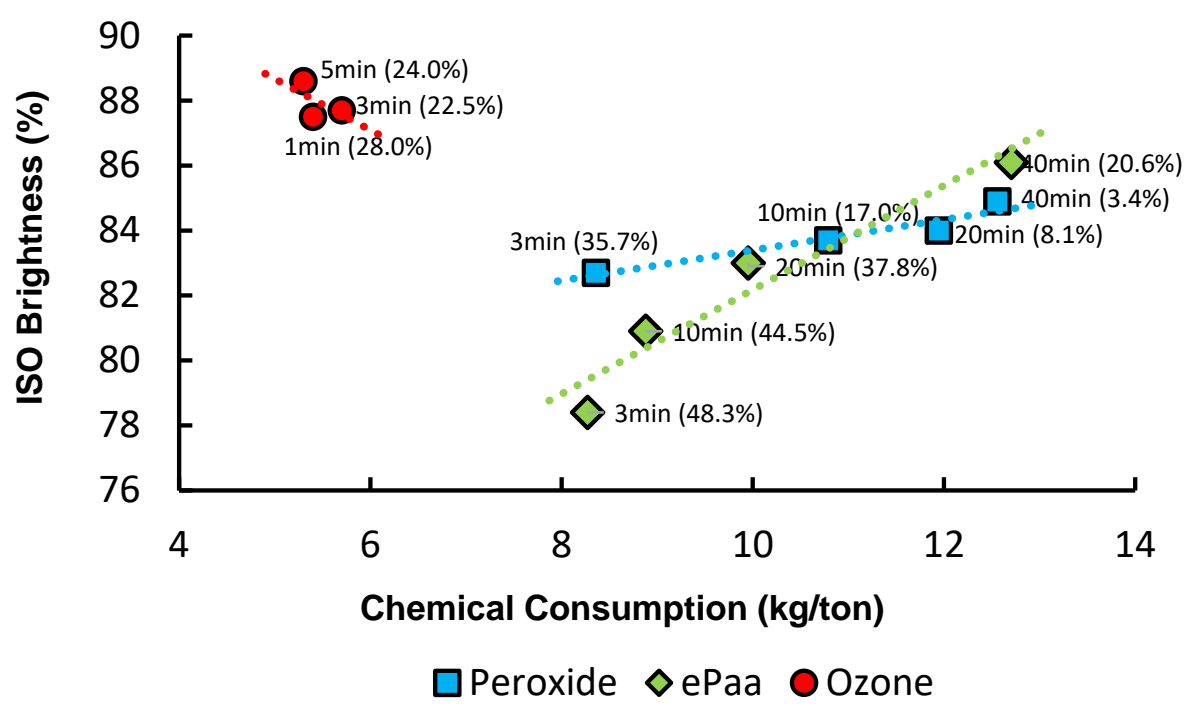

Fig. 3. ISO brightness \% as a function of the chemical consumption. Note: the times are bleaching times and percentage in parenthesis is the residual chemical amount; the starting brightness of the raw material was $57.0 \%$ ISO units.

Increasing the bleaching time of ozone from $1 \mathrm{~min}$ to $5 \mathrm{~min}$ only increased the brightness by approximately 1 ISO brightness unit. Therefore, the bleaching effect of ozone is fast and primarily occurs during the first minute. In these tests, it seems that greater than $20 \%$ of the introduced ozone was not consumed when a $0.7 \%$ dosage was used. Preliminary experiments showed that a dose of $0.6 \%$ was too low, yielding an ISO brightness of approximately $84 \%$, but the amount of residual chemicals was lower.

When using peroxide and peracetic acid, the highest brightness values occurred when using the longest bleaching time $(40 \mathrm{~min})$. Peracetic acid seemed to increase the brightness more than peroxide. After 20 min, continuation of the bleaching process for another 20 min further increased the brightness by approximately 1 ISO brightness unit for peroxide and by approximately 3 ISO brightness unit for peracetic acid. Therefore, prolonging the bleaching process when utilizing peracetic acid provided greater benefit compared to peroxide. It is possible that the peroxide was also consumed in some other reactions instead of the bleaching process, causing it to decompose during the bleaching process.

The residual amount of peroxide after 40 min was low (approximately 3\%), while the residual amount of peracetic acid after $40 \mathrm{~min}$ was approximately $20 \%$. It seems that in this study, among the bleaching agent dosages, peroxide was chosen as the most successful considering the low amount of residual chemicals, while peracetic acid requires longer reaction time to attain low residual amount. This work also showed that when 
bleaching residues of caramelized hemicelluloses, the increase in brightness is more effective than in bleaching lignin in traditional pulp mills.

Figure 4 shows a comparison of the bleaching agents when the OXE number was used to normalize different chemicals. It should be noted that the OXE number is only a relative measure and shows a comparison purely on a chemical basis. Different bleaching chemicals have different cost levels, and if comparison is made according to this, the results can be totally different.

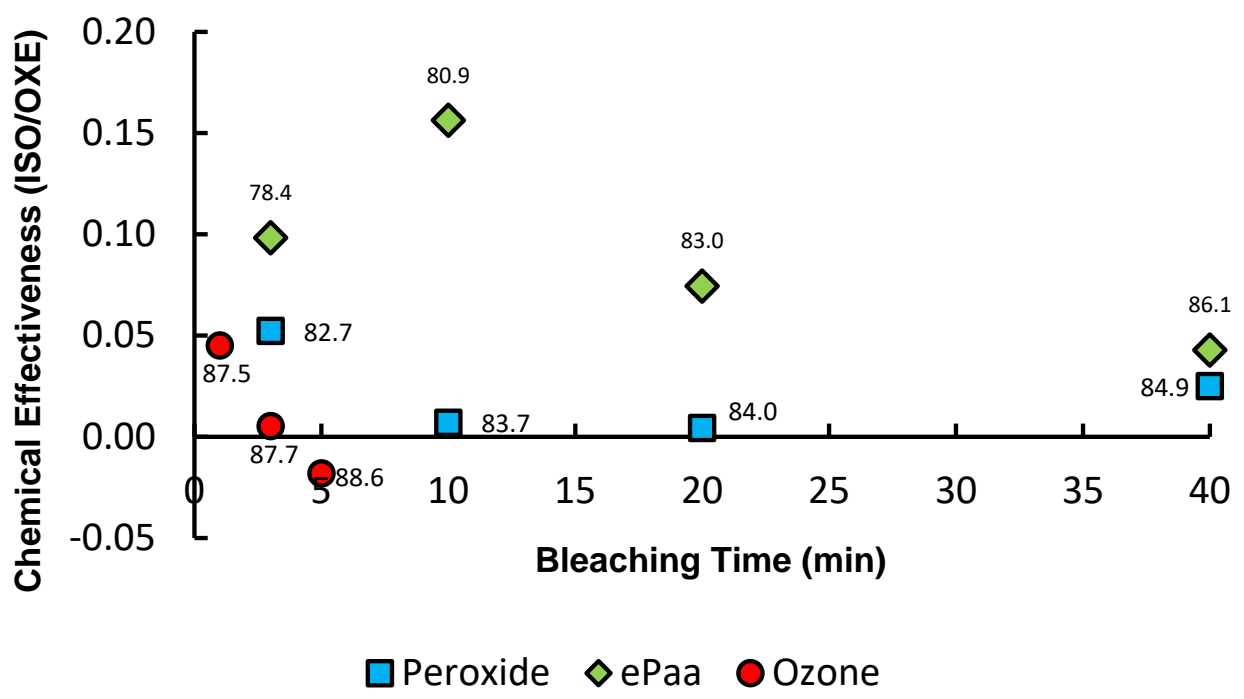

Fig. 4. Chemical effectiveness calculated based on the OXE number as a function of the bleaching time

Peracetic acid is a more effective chemical in terms of bleaching compared to peroxide if the OXE number is used as the comparison basis. After 5 min of bleaching, the effectiveness of peracetic acid almost doubled. After $10 \mathrm{~min}$ of bleaching, a majority of the effect of peroxide on the brightness has already occurred and prolonging the process an additional 30 min only yields an increase of 1.2 ISO brightness units, while peracetic acid yields an increase 5.2 of ISO brightness units. This fact is confirmed by the OXE comparison, where peracetic acid is effective during the entire bleaching process at increasing the brightness. As already discussed above, ozone rapidly reacts during the bleaching process, as early as during the first minute. Figure 4 shows this rapid reaction, but at the first measurement point its effectiveness has decreased below the other chemicals.

\section{Filtrate Fractions Analysis}

The total dissolved solids concentration (TDS) of the filtrate fraction of the pulp at the reference point, as well as in the case of ozone, were at $0.6 \mathrm{~g} / \mathrm{L}$; the TDS of peroxide was $5.0 \mathrm{~g} / \mathrm{L}$ and the TDS of peracetic acid was $3.5 \mathrm{~g} / \mathrm{L}$. The high TDS concentration of peroxide and peracetic acid is due to the addition of $\mathrm{NaOH}$ during the $\mathrm{pH}$ adjustment. The reducing effect of the $\mathrm{NaOH}$ level would have been the same. The reference point COD concentrations were at $670 \mathrm{mg} / \mathrm{L}$ and were even lower for the ozone (approximately 550 $\mathrm{mg} / \mathrm{L})$. Ozone appears to effectively oxidize all organic matter. However, the concentrations were considerably higher for peroxide $(3100 \mathrm{mg} / \mathrm{L})$ and peracetic acid (approximately $6700 \mathrm{mg} / \mathrm{L}$ ). The TOC concentrations were approximately one-third of the 
COD in each case. The high COD and TOC values of peracetic acid, compared to the peroxide filtrates, was attributed to the reaction kinetics of peracetic acid, where acetic acids are formed. In general, the concentrations in the filtrates did not appear to change much as the reaction proceeded for any of the bleaching chemicals used. At least in the case of peracetic acid, further treatment of the filtrate should be undertaken if bleaching is carried out on an industrial level. As such, it should not be directed to a wastewater treatment plant, especially if considerable volumes are utilized.

Table 3. Total Dissolved Solids (TDS), Chemical Oxygen Demand (COD), and Total Organic Carbon (TOC) Analysis Results for the Filtrate Fraction of the Microcrystalline Cellulose (MCC)

\begin{tabular}{|c|c|c|c|}
\hline & TDS $(\mathrm{g} / \mathrm{L})$ & COD $(\mathrm{mg} / \mathrm{L})$ & TOC $(\mathrm{mg} / \mathrm{L})$ \\
\hline Reference point, 0-test & 0.6 & 670 & 200 \\
\hline Ozone & 0.6 & 550 & 200 \\
\hline Peroxide & 5.0 & 3100 & 1200 \\
\hline Peracetic acid & 3.5 & 6700 & 2800 \\
\hline
\end{tabular}

Monosaccharide analysis of the filtrates showed that the hemicellulose contents of the filtrates varied greatly in different bleaching cases (as shown in Fig. 5).

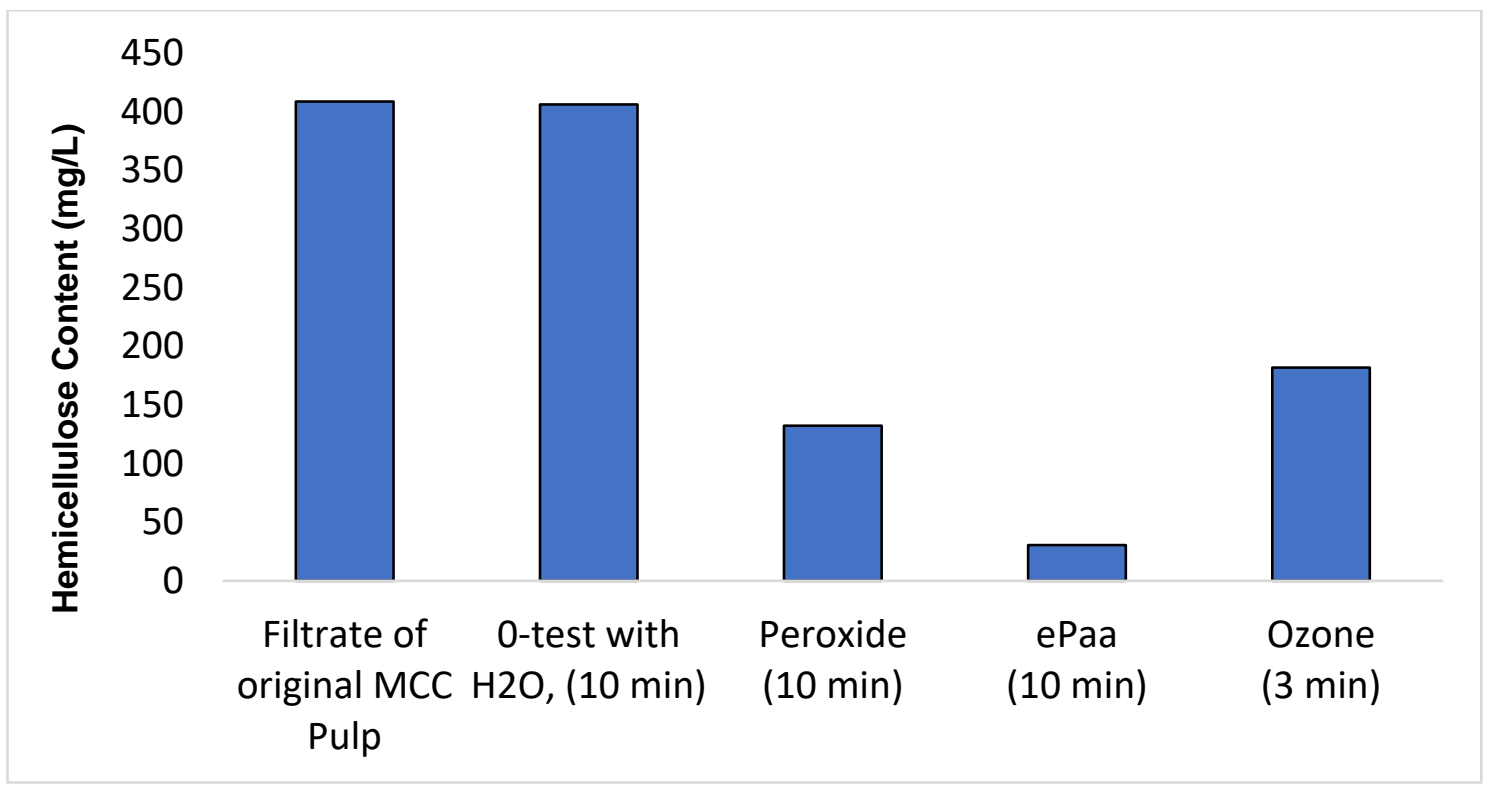

Fig. 5. Amount of monosaccharides in the filtrate samples from the various bleaching stages and original pulp (Note: consistency scaled to $10 \%$ )

The filtrate of the diluted original pulp and reference sample (0-test with water) contained approximately $400 \mathrm{mg} / \mathrm{L}$ of hemicelluloses. The filtrate of the original pulp is pressed out from the original MCC pulp. The filtrate of the 0-test is the filtrate when the original pulp and water have been mixed for $10 \mathrm{~min}$ in a Mark reactor and the filtrate sample extruded from the pulp through wire gauze after sampling. The hemicellulose content is rather low, so that it is difficult to suggest what biochemicals could be made of it, and the potential benefit could be lost if it had to be evaporated. For ozone, the 
concentrations were just under half of the reference point; for peroxide and peracetic acid they were less. For peracetic acid, the reaction seemed to consume almost all the hemicellulose. The primary components were xylose, glucose, and mannose (Figs. 6 and Fig. 7).

\section{Relative composition of the monosaccharides (\%)}

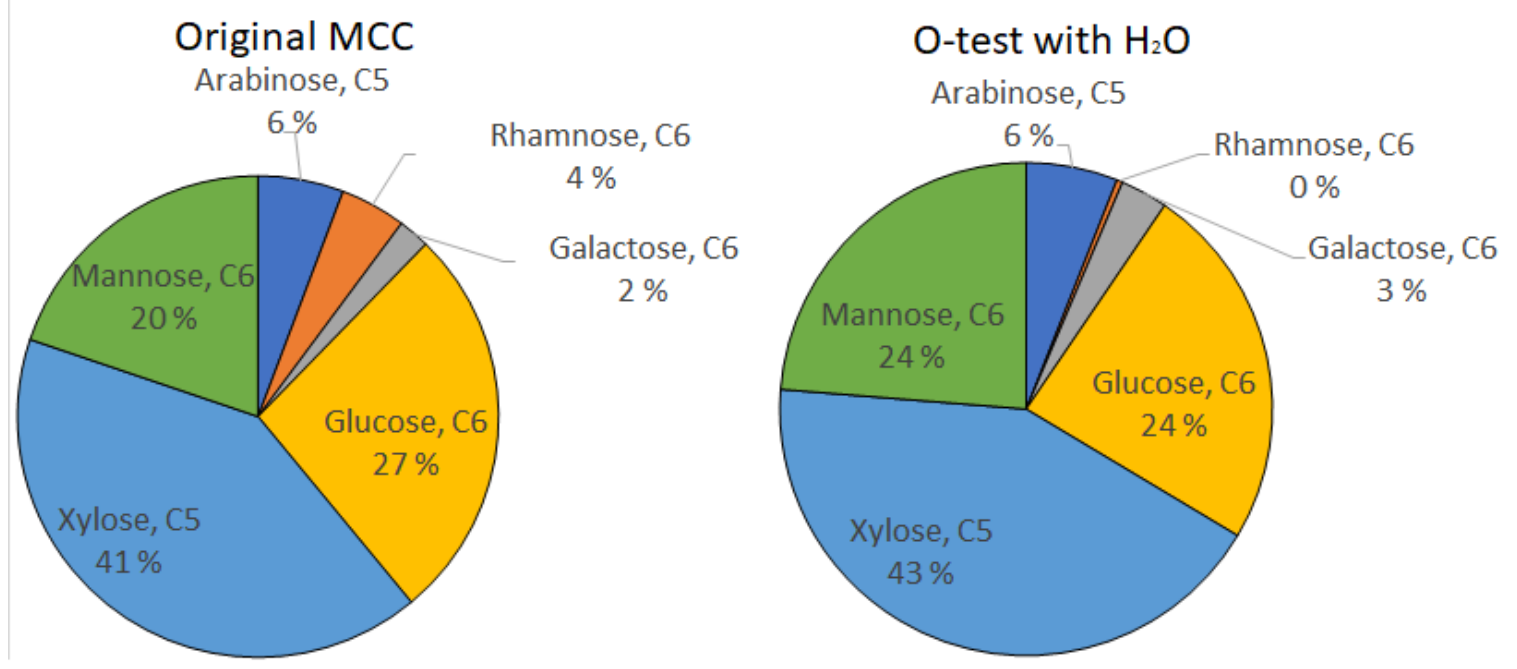

Fig. 6. Relative composition of the monosaccharides in the filtrate of the original MCC and O-test

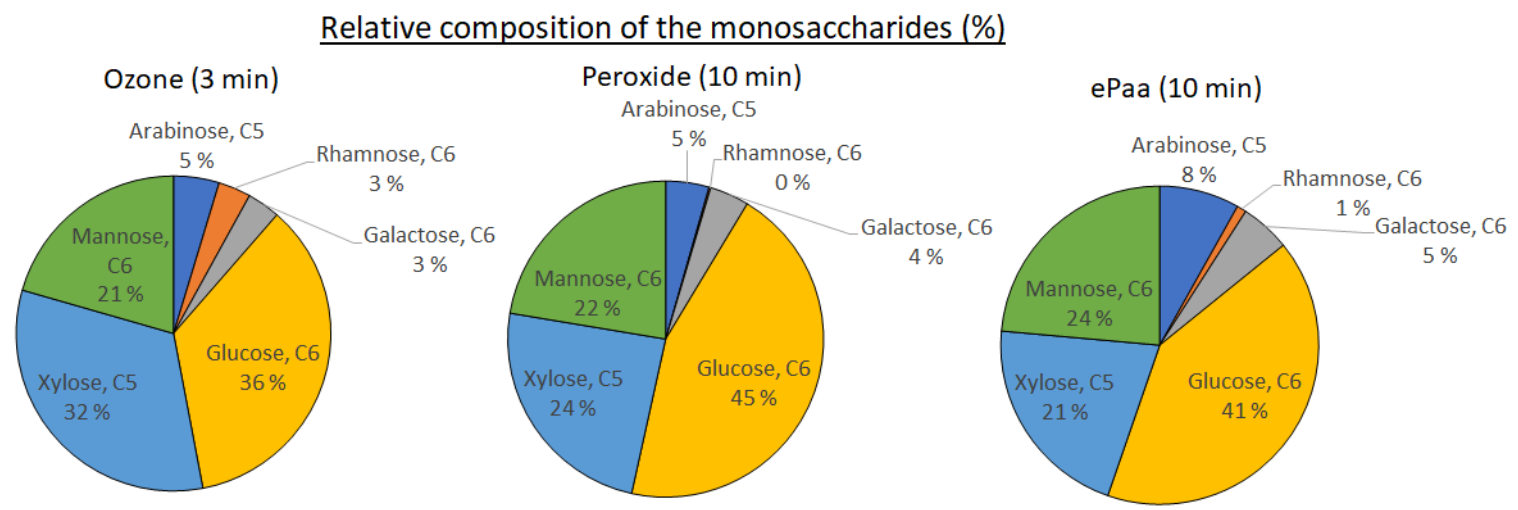

Fig. 7. Relative composition of the monosaccharides in the filtrate samples from the ozone, peroxide, and ePaa bleaching samples after the mentioned reaction times

In addition, arabinose, rhamnose, and galactose were found in the filtrates. The composition of the hemicellulose was similar to the composition obtained by Ristolainen and Alén (1998), where they characterized the composition of the TCF softwood line filtrates at the different bleaching stages. The most common monosaccharide in their study was xylose (40\% to $50 \%)$, and the composition of the other monosaccharides ranged from approximately $20 \%$ to a few percent, with mannose and glucose being the next most common.

Figures 6 and 7 also show how the relative composition of the monosaccharides varied after different bleaching processes versus the filtrates of the original MCC. The relative proportion of xylose $(\mathrm{C} 5)$ decreased, while the relative proportion of glucose $(\mathrm{C} 6)$ 
increased, in all cases. The proportion of mannose remained fairly constant in all cases, being approximately $20 \%$ of the composition. The multitude of oxidative degradation reactions taking place in the pulp during bleaching caused changes in the hemicellulose composition. In other words, aliphatic carboxylic acids were presumably also formed from pulp carbohydrates. This could be one of the reasons for the high COD level of ePaa, but low monosaccharide content.

\section{Comparison of the Different Brightness/Whiteness Measurement Methods}

The measured brightness and whiteness values of the different bleached MCC samples are shown in Table 4. The ISO brightness \% measured from the sheet was approximately 1 unit to 4 units lower than the corresponding value from the tablet. The sheet was pressed from wet MCC and dried in a condition room, whereas the tablet was pressed from dry powder. Thus, the surfaces of the sheet and tablet are physically different, which has an effect on the ISO brightness. The tablet ISO brightness reached the targeted $85 \%$ for almost every test point, excluding the short bleaching time points with peracetic acid and peroxide. Thus, it is possible to reach high brightness in the final MCC powder product with the bleaching chemicals used in this study.

Table 4. Measured Brightness and Whiteness Values of the Different Bleached Microcrystalline Cellulose (MCC) Samples

\begin{tabular}{|c|c|c|c|c|}
\hline & $\begin{array}{c}\text { ISO Brightness } \\
\text { Sheet (\%) }\end{array}$ & $\begin{array}{c}\text { ISO Brightness, } \\
\text { Tablet (\%) }\end{array}$ & $\begin{array}{c}\text { Y-brightness } \\
(\%)\end{array}$ & $\begin{array}{c}\text { Whiteness } \\
(\%)\end{array}$ \\
\hline $\mathrm{O}_{3}(1 \mathrm{~min})$ & 87.5 & 88.4 & 93.5 & 78.9 \\
\hline $\mathrm{O}_{3}(3 \mathrm{~min})$ & 87.7 & 88.2 & 93.1 & 77.2 \\
\hline $\mathrm{O}_{3}(5 \mathrm{~min})$ & 88.6 & 88.3 & 95.6 & 85.9 \\
\hline $\mathrm{ePaa}(3 \mathrm{~min})$ & 78.4 & 82.1 & 88.6 & 65.6 \\
\hline $\mathrm{ePaa}(10 \mathrm{~min})$ & 80.9 & 83.4 & 89.9 & 68.1 \\
\hline $\mathrm{ePaa}(20 \mathrm{~min})$ & 83.0 & 85.5 & 91.7 & 73.4 \\
\hline ePaa $(40 \mathrm{~min})$ & 86.1 & 87.5 & 93.2 & 77.7 \\
\hline Peroxide $(3 \mathrm{~min})$ & 82.7 & 85.6 & 91.1 & 70.9 \\
\hline Peroxide $(10 \mathrm{~min})$ & 83.7 & 86.8 & 92.1 & 74.2 \\
\hline Peroxide $(20 \mathrm{~min})$ & 84.0 & 85.9 & 92.2 & 74.8 \\
\hline Peroxide $(40 \mathrm{~min})$ & 84.9 & 87.0 & 92.7 & 76.2 \\
\hline
\end{tabular}

Moreover, Table 4 shows that both the Y-brightness and whiteness increased as the bleaching time increased. Thus, the Y-brightness and whiteness can both be utilized as criteria when the brightness and color of MCC is evaluated. Notably, the whiteness more rapidly decreased from $100 \%$ compared to the ISO-brightness and Y-brightness values. For example, the test point for peracetic acid after $40 \mathrm{~min}$ had a good ISO brightness of $87.5 \%$ and Y-brightness of $93.2 \%$, but the whiteness had dropped to $77.7 \%$.

As mentioned earlier, with the definition of MCC brightness being "white or almost white" and MCC producers having their own in-house methods for analysis, and it is difficult to compare the brightness results obtained here with those of commercial MCC grades. Thus, the tablet ISO brightness, Y-brightness, and whiteness of a few commercial MCCs were analyzed. The obtained values were approximately $80 \%$ to $89 \%, 89 \%$ to $95 \%$ and $65 \%$ to $84 \%$, respectively. These results further showed that the definition of MCC brightness is not particularly strict, and grades with considerably different brightnesses are

Kopra et al. (2021). "Bleaching of AaltoCell ${ }^{\mathrm{TM}}$ cellulose," BioResources 16(4), 7991-8005. 8001 
manufactured. Hence, the brightness values presented in this study are comparable with those of MCCs available on the market; therefore, bleached AaltoCell ${ }^{\mathrm{TM}} \mathrm{MCC}$ can compete against them in terms of its brightness.

\section{CONCLUSIONS}

1. The selected chlorine-free chemicals, i.e., ozone, peroxide, and peracetic acid, and doses achieved a sufficient ISO brightness value for microcrystalline cellulose (MCC) made via the AaltoCell ${ }^{\mathrm{TM}}$ process from normal paper pulp. Ozone seems to be the most suitable bleaching agent with a shorter reaction time and the highest brightness values.

2. The results showed that after bleaching with different bleaching agents, the chemical oxygen demand (COD), total organic carbon (TOC), and hemicellulose concentrations in the filtrate fraction greatly varied. This should be taken into account when recovery methods for hemicelluloses or purification methods for filtrates are being planned.

3. The results showed that the definition of MCC brightness is not strict and grades with drastically different brightnesses are manufactured. The target in all cases is to achieve MCCs with a sufficient level of ISO brightness that pleases human eyes.

\section{ACKNOWLEDGMENTS}

The research was carried out within the "Kuitu-MOD" project by the South-Eastern Finland University of Applied Sciences / FiberLaboratory. The project was funded by the European Regional Development Fund (ERDF) via the Regional Council of South-Eastern Finland and the participating companies. This study was initiated under a contract between the South-Eastern Finland University of Applied Sciences, the Aalto University, and Andritz Oy. The authors thank Liz Dexter for editing the manuscript, Marko Rasi for helping with ozone tests, and Anu Pihlajaniemi for helping with the data analysis. The authors are grateful to all participants involved with this study.

\section{REFERENCES CITED}

ASTM E308 (2018). "Standard practice for computing the colors of objects by using the CIE system," ASTM International, West Conshohocken, PA.

ASTM E313 (2020). "Standard practice for calculating yellowness and whiteness indices from instrumentally measured color coordinates," ASTM International, West Conshohocken, PA.

Author unknown (2020). Analytical method for peracetic acids: Determination of hydrogen peroxide and peracetic acid content by titration. Microsoft Word Determination of hydrogen peroxide and peracetic acid content by titration (evonik.com), Evonik Operations GmbH.

Battista, O. A. (1950). "Hydrolysis and crystallization of cellulose," Industrial \& Engineering Chemistry 43(3), 502-507. DOI: 10.1021/ie50483a029

Battista, O. A., Hill, D., and Smith, P. A. (1961). "Level-off D.P cellulose products," U. S. Patent No. 2978446A. 
Bergfeld, M. J., and Seifert, J. (1996). "Process for the preparation of level-off DP cellulose," U. S. Patent No. 5543511A.

Carter, E. C., Schanda, J. D., Hirschler, R., Jost, S., Luo, M. E., Melgosa, M., Ohno, Y., Pointer, M. R., Rich, D. C., Viénot, F., et al. (2018). Colorimetry, $4^{\text {th }}$ Edition, International Commission on Illumination (CIE), Vienna, Austria.

Chirat, C., Lachenal, D., and Mateo, C. (2003). "Factors affecting the bleaching ability of pulps," in: Proceedings of the EFPG Days, 8-9 April, Grenoble, France.

Cui, S. W. (2005). Food carbohydrates: Chemistry, Physical Properties and Applications, CRC Press, Boca Raton, FL.

Dahl, O., Vanhatalo, K., and Parviainen, K. (2016). "Method to product microcellulose," U. S. Patent No. 9469695B2.

DeLong, E. (1986). "Method of producing level off DP microcrystalline cellulose and glucose from lignocellulosic, “ E. P. Patent No. 0170530A2.

European Directorate for the Quality of Medicines \& HealthCare (2011), The European pharmacopoeia 7.0 Volumes 1 and 2 Set $7^{\text {th }}$ edition, Cellulose, microcrystalline, $p$. 1634, ISBN-10, 9287167001.

Food and Agriculture Organization of the United Nations (FAO) (1996). "Microcrystalline cellulose," (http://www.fao.org/docrep/W6355E/w6355e01.htm), Accessed March 13, 2013.

Frangioni, G., and Frangioni A. P. (2016). "Method for preparing microcrystalline cellulose," U. S. Patent No. 9303093B2.

Girisuta, B., Janssen, L. P. B. M., and Heeres, H. J. (2006). "A kinetic study on the decomposition of 5-hydroxymethylfurfural into levulinic acid," Green Chemistry 2006(8), 701-709. DOI: 10.1039/B518176C

Grundelius, R. N. (1993). "Oxidation equivalents, OXE - An alternative to active chlorine,” TAPPI Journal 76(1), 133-135.

Ha, E. Y. W., and Landi, C. D. (1998). "Method for producing microcrystalline cellulose," U. S. Patent No. 5769934A.

Hanna, M., Biby, G., and Miladinov, V. (2001). "Production of microcrystalline cellulose by reactive extrusion," U. S. Patent No. 6228213B1.

Hodge, J. E. (1953). "Dehydrated foods: Chemistry of browning reactions in model systems," Journal of Agricultural and Food Chemistry 1(15), 928-943. DOI: 10.1021/jf60015a004

Ioelovich, M., and Leykin, A. (2005). "Method of producing microcrystalline cellulosecontaining compositions," U. S. Patent No. 20050239744A1.

ISO 13320 (2009). "Particle size analysis - Laser diffraction methods," International Organization for Standardization, Geneva, Switzerland.

ISO 15705 (2002). "Water quality - Determination of the chemical oxygen demand index (ST-COD) - Small-scale sealed-tube method," International Organization for Standardization, Geneva, Switzerland.

ISO 2469 (2014). "Paper, board and pulps - Measurement of diffuse radiance factor (diffuse reflectance factor)," International Organization for Standardization, Geneva, Switzerland.

ISO 638 (2021). "Paper, board, pulps and cellulosic nanomaterials - Determination of dry matter content by oven-drying method - Part 1: Materials in solid form," International Organization for Standardization, Geneva, Switzerland.

ISO 8245 (1999). "Water quality - Guidelines for the determination of total organic carbon (TOC) and dissolved organic carbon (DOC)," International Organization for 
Standardization, Geneva, Switzerland.

Jollez, P., Chornet, E., Schaible, D., and Brinkman, I. C. (2002). "Process for producing microcrystalline cellulose with a desired DP," WO Patent No. 2002036875A1.

Kupiainen, L. (2012). Dilute Acid Catalyzed Hydrolysis of Cellulose-Extension to Formic Acid, Ph.D. Dissertation, University of Oulu, Oulu, Finland.

Lachenal, D., and Chirat, C. (2005). "On the efficiency of the bleaching chemicals for kraft pulp," Cellulose Chemistry and Technology 39(5), 151-156.

Ledl, F., and Schleicher, E. (1990). "New aspect of the Maillard reaction in foods and in the human body," Angewandte Chemie International Edition in English 29(6), 65594. DOI: 10.1002/anie.199005653

Lichtenthaler, F. W. (2011) "Carbohydrates: Occurrence, structures and chemistry," in: Ullmann's Encyclopedia of Industrial Chemistry $7^{\text {th }}$ Edition, B. Elvers (ed.), WileyVCH, Weinheim, Germany, pp. 617-646.

Mattheson, J., Guo, J. X., and Shaver, L. (2002). "Microcrystalline cellulose manufacture," WO Patent No. 2002057540.

Nguyen, X. T, and Tan, Z. (2006). "Surface treatment with texturized microcrystalline cellulose microfibrils for improved paper and board," U. S. Patent No. 7037405B2

Nguyen, X. T. (2004). "Process for preparing microcrystalline cellulose," U. S. Patent No. 7005514B2.

Ristolainen, M., and Alén, R. (1998). "Characterization of effluents from TCF bleaching of softwood kraft pulp," TAPPI Journal 81(9), 195-198.

SCAN-CM 15 (1998). "Viscosity in cupri-ethylenediamin (CED) solution," Scandinavian Pulp, Paper and Board, Stockholm, Sweden.

SCAN-CM 15 (1999). "Viscosity in cupriethylenediamine solution," Scandinavian Pulp, Paper and Board, Stockholm, Sweden.

SCAN-P 89 (2003). "Preparation of tablets for the measurement of ISO brightness, Yvalue and colour $\left(\mathrm{C} / 2^{\circ}\right)$," Scandinavian Pulp, Paper and Board, Stockholm, Sweden.

Schaible, D., and Brinkman, I. (2003). "Process for producing microcrystalline cellulose,” U. S. Patent No. 20030089465A1.

Schaible, D., and Sherwood, B. (2005). "Treatment of pulp to produce microcrystalline cellulose," U. S. Patent No. 20050145351A1.

Sixta, H. (2006). "Multistage kraft pulping," in: Handbook of Pulp, H. Sixta (ed.), WileyVCH, Weinheim, Germany, pp. 325-365.

Sluiter, A., Hames, B., Ruiz, R., Scarlata, C., Sluiter, J., and Templeton, D. (2006). Determination of Sugars, Byproducts, and Degradation Products in Liquid Fraction Process Samples (NREL/TP-510-42623), National Renewable Energy Laboratory, Golden, CO.

Sumerskii, I. V., Krutov, S. M., and Zarubin, M. Y. (2010). "Humin-like substances formed under the conditions of industrial hydrolysis of wood," Russian Journal of Applied Chemistry 83, 320-327. DOI: 10.1134/S1070427210020266

Tan, Z., Eustace, S., Sestrick, M., and Ondov, J. (2016). "Method of making bleached microcrystalline cellulose," WO Patent No. 2016182867A1.

Toshkov, T. S., Gospodinov, N. R., and Vidimski, E. P. (1976). "Method of producing microcrystalline cellulose," U. S. Patent No. 3954727A.

Valchev, I., Yavorov, N., and Todorova, D. (2020). "Producing bleached microcrystalline cellulose by two-stage dilute acid hydrolysis," Cellulose Chemistry and Technology 54(3-4), 259-264. DOI: 10.35812/CelluloseChemTechnol.2020.54.27 
Vanhatalo, K. M., and Dahl, O. P. (2014). "Effect of mild acid hydrolysis parameters on properties of microcrystalline cellulose," BioResources 9(3), 4729-4740. DOI: 10.15376/biores.9.3.4729-4740

Article submitted: June 4, 2021; Peer review completed: September 11, 2021; Revised version received and accepted: October 11, 2021; Published: October 14, 2021.

DOI: 10.15376/biores.16.4.7991-8005 